\title{
Study on Dynamic Response Characteristics and Damage Mechanism of Tunnel Lining at Entrance of Shallow Bias Tunnel
}

\author{
Lin Li, ${ }^{1}$ Xiaodan Guo, ${ }^{1}$ Zuyin Zou ${ }^{(D},{ }^{1}$ Zhanyuan Zhu, ${ }^{1}$ Zihong Guo, \\ Weimin Xiao, ${ }^{1}$ and Deping Guo ${ }^{2}$ \\ ${ }^{1}$ School of Civil Engineering, Sichuan Agricultural University, Dujiangyan 611830, China \\ ${ }^{2}$ Sichuan Railway Investment Group Co., Ltd., Chengdu 610094, China \\ Correspondence should be addressed to Zuyin Zou; 382358357@qq.com
}

Received 1 July 2021; Revised 19 August 2021; Accepted 26 August 2021; Published 25 September 2021

Academic Editor: Honglue Qu

Copyright ( $\odot 2021$ Lin Li et al. This is an open access article distributed under the Creative Commons Attribution License, which permits unrestricted use, distribution, and reproduction in any medium, provided the original work is properly cited.

\begin{abstract}
The structural damage of the lining structure at the entrance of a tunnel is the most common instability problem. The instability problem may cause dynamic effects such as earthquakes and blasting. Based on the seismic damage data collected from previous major earthquakes at the entrance of shallow-buried tunnel, the shaking table test and numerical simulation are used to analyze dynamic response characteristics and damage evolution characteristics of the tunnel in the shallow-buried hole at $30^{\circ}$. The study revealed the stress characteristics of tunnel lining and the mechanism of structural damage under earthquake excitation. The research results show that the biased tunnel $\left(30^{\circ}\right)$ is susceptible to damage on the unsymmetrical loading side, the biased ground surface leads to acceleration, and high speed also significantly increases the effect. The biased side leg of the tunnel lining cross section is a location with a large internal force distribution. The biased tunnel has a relatively unfavorable internal force value distribution and a larger peak, and the peak at the larger bias side has the largest peak value. The skewback and spandrel portion of the biased tunnel lining load are more likely to be damaged.
\end{abstract}

\section{Introduction}

The tunnel opening section is an area that is often subject to changing conditions during the transition from the ground to the underground, it is inevitable that the tunnel encounters a bias phenomenon due to insufficient precautions or poor dynamic effects. The so-called unsymmetrical loading tunnel refers to the tunnel with its support being subject to bias load, where its surrounding rock pressure exhibits apparent unevenness caused by topographical factors, geological factors, and engineering factors [1].

The seismic damage at the entrance of an unsymmetrical loading tunnel mainly includes the collapse of the slope at the entrance and cracks in the lining structure [2]. There are many reports about the damage of tunnel openings caused by earthquakes. For example, there was an opening of the tunnel that was damaged during the 1999 Chi-Chi earthquake [3-5] (Figure 1). In 2008, there were a large number of earthquakes in the Wenchuan earthquake in China. Serious damage occurred at the opening section of the unsymmetrical loading tunnel [6-8] (Table 1 and Figure 2). The characteristics of the epicenter at the opening of the unsymmetrical loading tunnel section became the focus of research and serves as the decisive place for seismic fortification.

The seismic response of underground structures has been studied by many researchers using various methods, including theoretical analysis, numerical simulation, and physical model tests [9-13]. On-site investigation of the Kumamoto earthquake by Zhang et al. [14] showed that the main seismic damage was cracks seen at the entrance of tunnel lining. Genis and Jai et al. [8, 15-17] performed dynamic response analysis on the stability of the tunnel opening. Wang et al. [18] proposed a method for identifying damage indicators of tunnel lining structures based on wavelet residual force vector. Varma et al. [19] established a universal discrete element coding model, proving that shallow-buried tunnel linings are more vulnerable to 


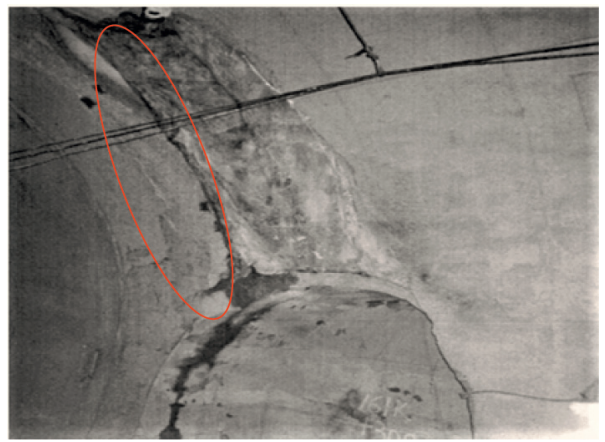

FIGURE 1: Lining crack of tunnel in chi-chi earthquake [4].

TABLE 1: Investigation results of seismic damage for tunnels during Wenchuan earthquake.

\begin{tabular}{|c|c|c|c|c|}
\hline Tunnel name & $\begin{array}{l}\text { Length } \\
(\mathrm{m})\end{array}$ & $\begin{array}{c}\text { Distance to epicenter } \\
(\mathrm{km})\end{array}$ & $\begin{array}{c}\text { Fault } \\
\text { amount }\end{array}$ & Destruction feature \\
\hline Longxi & 3691 & $0.5-2$ & 1 & $\begin{array}{l}\text { Rock falls; pavement uplift; lining crack; lining dislocation; cable } \\
\text { trench; water leakage }\end{array}$ \\
\hline Taoguan & 625 & 15 & 0 & Portal failure; rock falls; headwall damage; lining crack \\
\hline Longdongzi & 1071 & 2 & 4 & $\begin{array}{l}\text { Rock falls; pavement uplift; lining crack; lining dislocation; cable } \\
\text { trench; water leakage }\end{array}$ \\
\hline Shaohuoping & 451 & 1 & 1 & $\begin{array}{c}\text { Portal failure; rock falls; headwall damage; lining crack; lining } \\
\text { dislocation; water leakage }\end{array}$ \\
\hline Zaojiaowan & 1926 & 5 & 0 & $\begin{array}{c}\text { Portal failure; headwall damage; lining crack; lining dislocation; cable } \\
\text { trench; water leakage }\end{array}$ \\
\hline Caopo & 759 & 20 & 0 & Portal failure; rock falls; lining crack; cable trench; water leakage \\
\hline Dankanliangzi & 1567 & 24 & 1 & portal failure; rock falls; headwall damage \\
\hline Zipingpu & 4090 & 5 & 10 & Rock falls; pavement uplift; lining crack; lining dislocation; cable trench \\
\hline
\end{tabular}

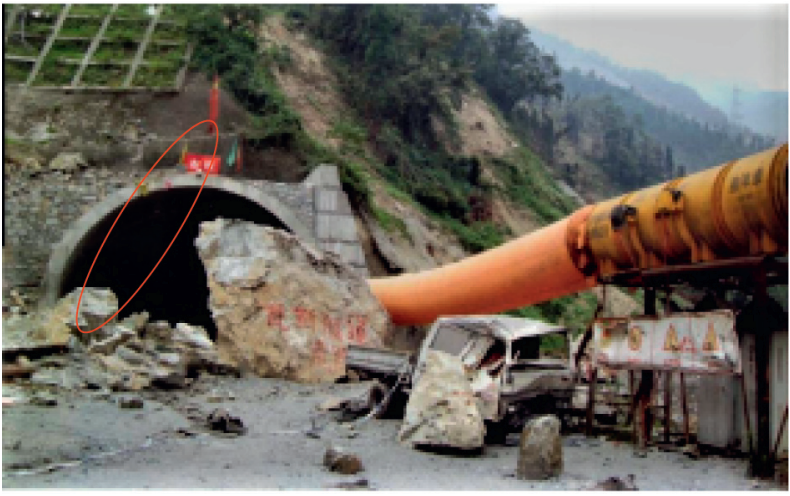

(a)

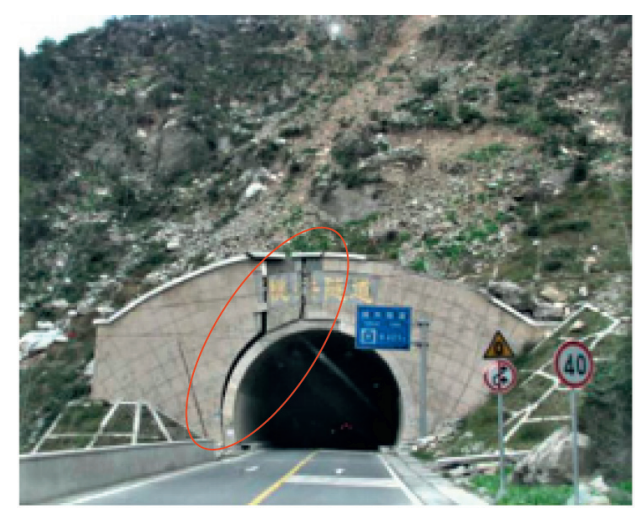

(b)

Figure 2: Damage patterns of tunnel linings during the Wenchuan earthquake 2008, China. (a) Damage at the entrance of Longxi tunnel [8]. (b) Cracking at the portal of Taoguan tunnel [7].

damage under seismic loads. Wang et al. [20] performed a series of shaking table tests on a scaled-up tunnel model under earthquake excitation to identify damage to the tunnel lining. Wang et al. [21] carried out a large-scale shaking table model test of a small-clearance shallow-buried biased tunnel, finding that the acceleration amplification coefficient and change trend of the left-hole lining are quite different compared with the right-hole lining. Most of the previous research studies are designed to verify the analysis method and provide experimental data regarding the ultimate stability of the tunnel. However, the study has not been extensively performed to the damage mechanism of the earthquake on the tunnel lining of the shallow-buried unsymmetrical loading tunnel.

In this paper, the shaking table test and numerical simulation are combined to study the lining damage mechanism of the shallow-buried tunnel opening section under the condition of $30^{\circ}$ bias angle and $60^{\circ}$ elevation slope. First, the shaking table model test is used to study the damage characteristics of the tunnel lining of the shallow- 
buried bias tunnel. Then, the dynamic finite element analysis method is used to analyze the characteristics, deformation, and internal force response laws of the full-time dynamic response of the tunnel lining of the shallow-buried bias tunnel. Finally, the simulation results are compared with the model test results to prove the rationality of the shaking table test and the reliability of the numerical simulation.

\section{Test Plan}

2.1. Model Test Device. The tunnel model is built in a rigid, sturdy box with a length, width, and height of $1.3 \mathrm{~m}, 1.0 \mathrm{~m}$, and $1.0 \mathrm{~m}$, respectively (Figure $3(\mathrm{~b})$ ), which is anchored on a shaking table (Figure 3(c)). The main parameters of the shaking table are shown in Table 2 . With the direction perpendicular to the excitation direction, the wall of the box is lined with a molded polystyrene foam board with a thickness of $70 \mathrm{~mm}$. Meanwhile, a smooth PVC film is pasted on the box walls at both ends of the model to reduce friction resistance on the surface where box comes in contact with soil (Figure 3(a)). A layer of crushed stone is laid on the bottom of the model box to increase the frictional resistance on the contact surface, so as to avoid relative sliding of the bottom plate of the model body when excited (Figure 3(b)).

2.2. Model Material Parameters. For the model test of rock mass materials, the geometric dimensions, boundary conditions and acting loads of the model, the bulk density, strength and deformation characteristics of the model rock mass, etc. must meet the similarity requirements expressed as follows [22]:

$$
\begin{aligned}
& C_{\sigma}=C_{l} C_{\gamma}, \\
& C_{\sigma}=C_{E} C_{\varepsilon}, \\
& C_{\mu}=1, \\
& C_{\delta}=C_{l} C_{\varepsilon},
\end{aligned}
$$

where $C_{\sigma}$ is stress similarity ratio, $C_{l}$ is geometric similarity ratio, $C_{E}$ is elastic modulus similarity ratio, $C_{\mu}$ is Poisson's similarity ratio, $C_{\gamma}$ is bulk density similarity ratio, $C_{\varepsilon}$ is strain similarity ratio, and $C_{\delta}$ is deformation similarity ratio. $C$ is the similarity ratio of physical parameter between the model and the prototype, respectively. Other ratios were calculated according to their relations with the basic ratios, as shown in Table 3.

The subscripts $m$ and $p$ represent the model and prototype, respectively, and $C_{l}, C_{\rho}$, and $C_{a}$ represent the similarity ratios of geometry, density, and acceleration, respectively. This study takes $C_{l}$ and $C_{\rho}$ as $1 / 50$ and 1 , respectively.

According to the orthogonal test theory, it is determined that the main materials of the surrounding rock are aggregate and cement. The aggregate is composed of fine sand and the cement is composed of gypsum and lime. The fine sand: cement $=4: 1$ and gypsum: lime $=7: 3$. The water content accounts for about $13 \%$. The similar materials for lining use gypsum with similar mechanical properties as concrete. According to existing research results, water is used. Based on the obtained similarity ratio, water: gypsum $=1: 1.5$. Material mechanical parameters of surrounding rock and lining model: the surrounding rock material has bulk density $17 \mathrm{kN} / \mathrm{m}^{3}$, cohesion $2 \mathrm{kPa}$, internal friction angle $25^{\circ}$, elastic modulus $0.035 \mathrm{Gpa}$, and Poisson's ratio 0.37 and lining material has bulk density $24 \mathrm{kN} / \mathrm{m}^{3}$, elastic modulus $0.56 \mathrm{Gpa}$, and Poisson's ratio 0.2. The test process is shown in Figure 4.

2.3. Test Introduction. In the test, the El-Centro wave is used as the input wave of the shaking table. The input seismic wave is selected, as shown in Figure 5. Before excitation, the white noise is scanned with a peak value of $0.07 \mathrm{~g}$ to make the model compact. In each subsequent set of experiments, a white noise scan was also entered to observe the changes in the dynamic characteristics of the system. Load along the cross section of the tunnel increases the input acceleration peak value $(0.1 \mathrm{~g})$ step by step. Before each load, a small amplitude $(0.07 \mathrm{~g})$ white noise excitation was input, as shown in Table 4.

The sensors used in shake table tests include accelerometers and strain gauges. The accelerometers and strain gauges were used to measure acceleration and strain on and around the tunnel lining, respectively. The sensor arrangement is also different at each test due to different test objectives. Figure 6 shows the arrangement of the instruments during the test phase. The accelerometer A01 is mounted directly on the shake table and keeps a record of the history of the input-based acceleration of the excitation. The accelerometers are arranged at the left- and right-arch shoulders above the tunnel lining; strain gauges are arranged at the left and right spandrel and skewback of the tunnel lining.

\section{Analysis of Test Results}

3.1. Acceleration Response Characteristics of Lining Structure. By comparing and analyzing the Fourier spectra of accelerations of the left and right spandrel of the tunnel lining of Figure 7 and 8, it can be found that the Fourier spectra of the tunnels with the same peak acceleration of the left and right spandrel are similar. Compared with the same peak acceleration of the left and right abutments, the right abutment on the biased surface facing the empty slope aggravates the dynamic stress response of the tunnel lining, and the peak value of the Fu-type spectrum is greater than the left abutment value. By analyzing the Fourier spectrum curves of different peak accelerations on the same side, it can be found that the dynamic response of the tunnel lining is positively correlated with the acceleration peak. The larger the acceleration peak, the more intense the Fourier spectrum attenuation, which also increased the peak value.

3.2. Failure Morphology of Tunnel Lining. During the test, the high-speed camera was used to record the damage process on the front and side of the tunnel section. After each 


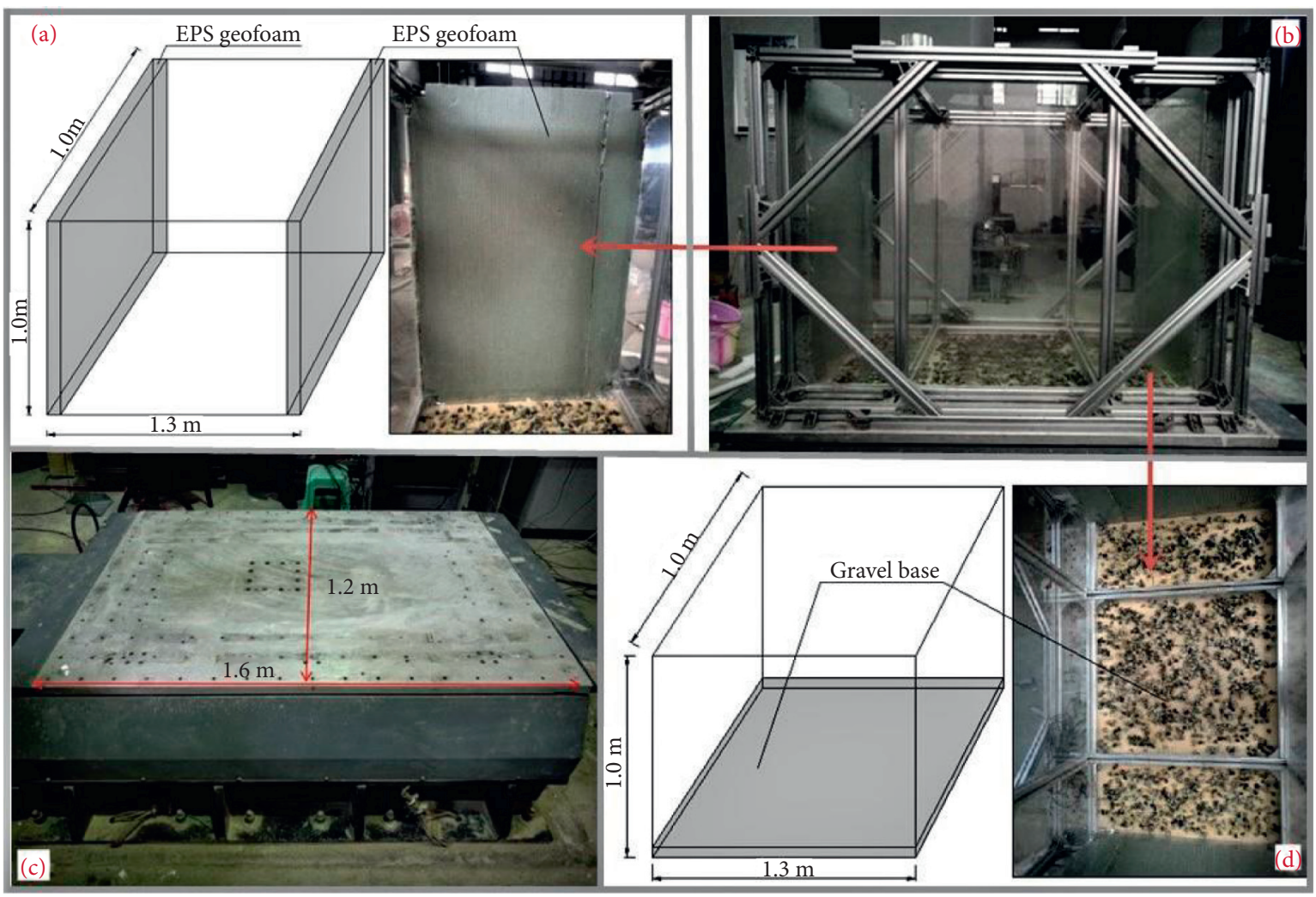

Figure 3: Model test device. (a) Polystyrene foam board. (b) Model box. (c) Shaking table. (d) Grave base.

TABLE 2: Main parameters of the shaking table.

\begin{tabular}{lc}
\hline Parameters & Specification \\
\hline Platform size & $1.6 \mathrm{~m} \times 1.2 \mathrm{~m}$ \\
Degree of freedom of motion & Single degree of freedom \\
Load capacity & $1.5 \mathrm{t}$ \\
Maximum displacement and & $\pm 1.5 \mathrm{~m}, \pm 1.0 \mathrm{~g}$ \\
acceleration & $0.01-10 \mathrm{~Hz}$ \\
Working frequency &
\end{tabular}

TABLE 3: The similar constants.

\begin{tabular}{lcc}
\hline Physical quantity & Similar relation & Similar constants \\
\hline$L$ & $C_{L}$ & $1 / 50$ \\
$\rho$ & $C_{\rho}$ & 1 \\
$E$ & $C_{E}$ & $1 / 50$ \\
$v$ & $C_{v}$ & 1 \\
$t$ & $C_{t}=C_{L} C_{\rho}^{0.5} C_{E}^{-0.5}$ & 0.141 \\
$a$ & $C_{a}=C_{L}^{-1} C_{\rho}^{-1} C_{E}$ & 1 \\
$u$ & $C_{u}=C_{L} C_{\varepsilon}$ & $1 / 50$ \\
$\sigma$ & $C_{\sigma}=C_{E}$ & $1 / 50$ \\
$\varepsilon$ & $C_{\varepsilon}=C_{E}^{-1} C_{L} C_{\gamma}$ & 1 \\
\hline
\end{tabular}

excitation is completed, each damage status of the tunnel lining under earthquake effect must be checked, and the distribution of cracks must be carefully recorded. Figure 9 shows the crack expansion of a tunnel lining under an earthquake with increased intensity. Cracks appeared in the tunnel lining at a level of $0.4 \mathrm{~g}$. Subsequently, existing cracks were observed at the shoulder of the tunnel lining and new cracks appeared at a strength level of $0.5 \mathrm{~g}$. The existing cracks was further expanded, and inclined cracks appeared at the strength level of $0.5 \mathrm{~g}$. Figure 8 displays the distribution of final crack and damage details. Cracks appeared at skewback, side wall, and spandrel of tunnel lining under earthquake effect.

3.3. Structural Damage of Tunnel Lining. It can be seen from Figure 10 that the peak value of the axial force almost appears at the right skewback. The internal force of the peak right is greater than that of left skewback, and a larger axial force value appears when the pressure is greater. Meanwhile, the axial force values are all pressure effects. The internal force of the bending moment demonstrates positive and negative alternatives, indicating that the tunnel lining is subjected to repeated tensile and compressive cyclic loads under ground motion action. The load is reflected by alternating tensile and compressive stresses. As the fatigue load and the compressive performance of the concrete is far greater than the tensile performance, thus the lining structure is often prone to tensile damage. In summary, it can be seen that the right side of the tunnel lining is the internal force of control section, and the skewback is most likely to be damaged and the damage response of the spandrel is also large under earthquake effect. 


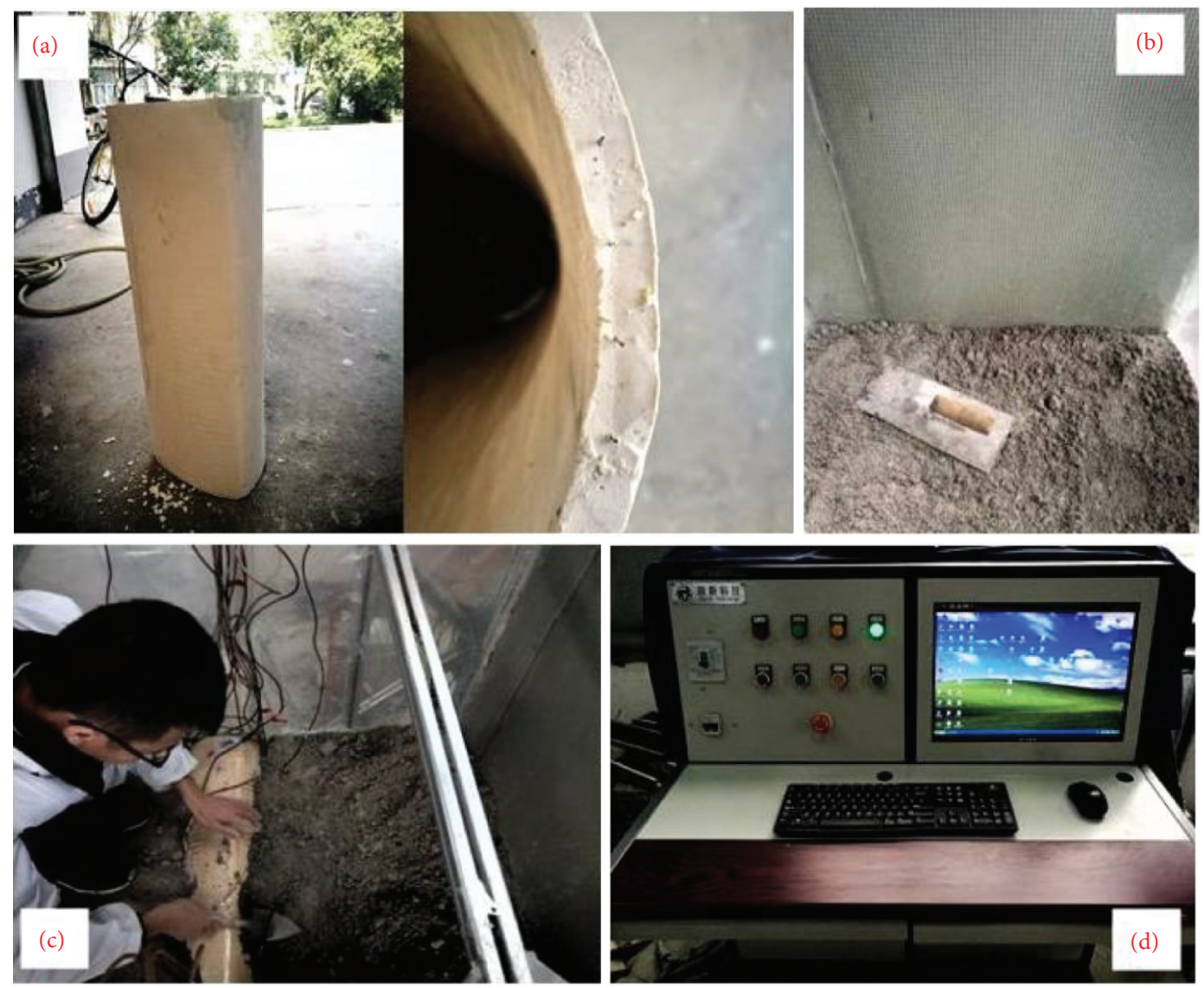

Figure 4: Model test setup. (a) Lining model. (b) Smoothing of lining. (c) Pouring surrounding rock. (d) Test operating platform.
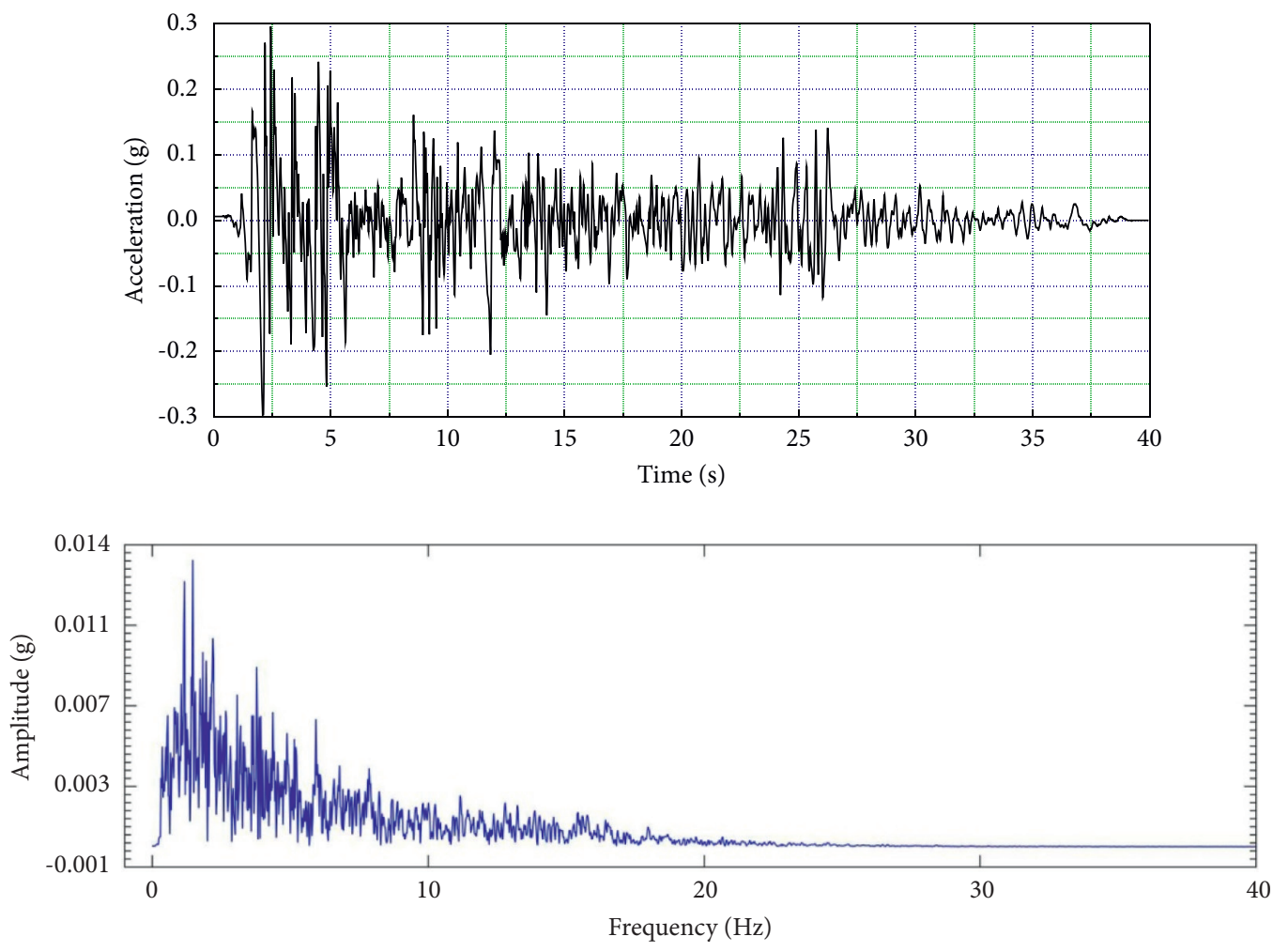

FIgURE 5: EL wave: acceleration-time histories and its corresponding Fourier spectrum. 
TABLE 4: Loading sequence for the shaking table tests.

\begin{tabular}{lcc}
\hline Test ID & Input waveform & \\
\hline 1 & EL wave & 0.1 \\
2 & EL wave & 0.2 \\
3 & EL wave & 0.3 \\
4 & EL wave & 0.4 \\
5 & EL wave & 0.5 \\
\hline
\end{tabular}
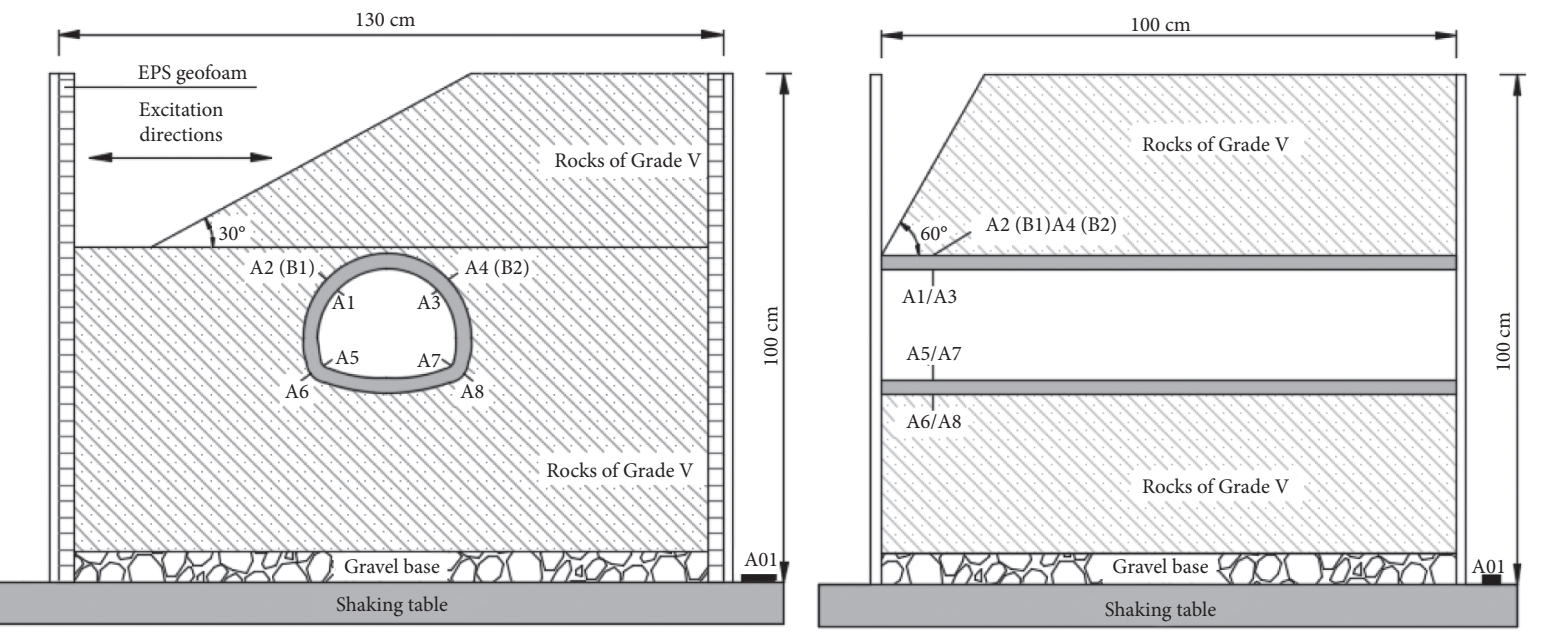

FigURE 6: Surrounding rock and layout of transducers (B/C), strain gauges; (A), accelerometer).

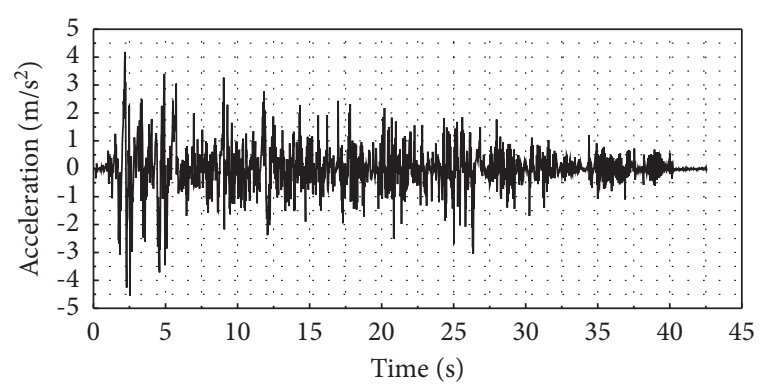

$-\mathrm{A} 1$

(a)

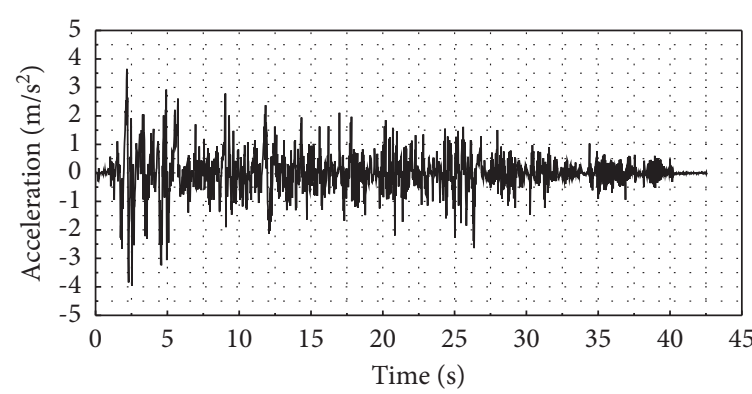

A7

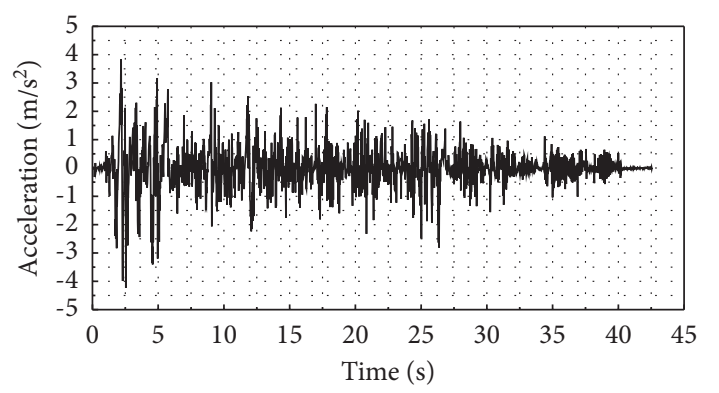

$-\mathrm{A} 3$

(b)

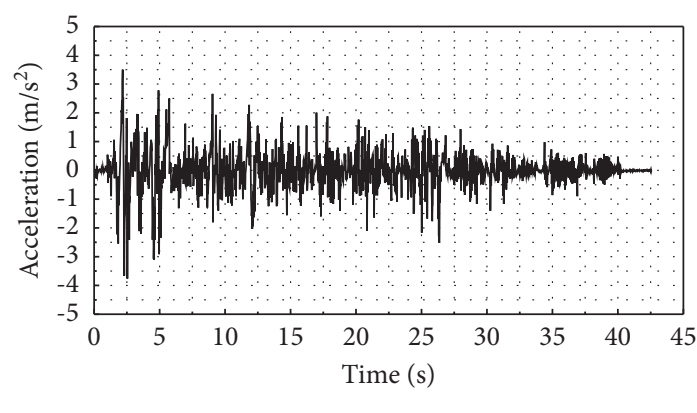

(d)

Figure 7: Acceleration spectrum curve of different measuring points. (a) $0.3 \mathrm{~g} \mathrm{~A}$ acceleration-time history. (b) $0.3 \mathrm{~g}$ A3 acceleration-time history. (c) $0.3 \mathrm{~g} \mathrm{A7}$ acceleration-time history. (d) $0.3 \mathrm{~g}$ A5 acceleration-time history. 


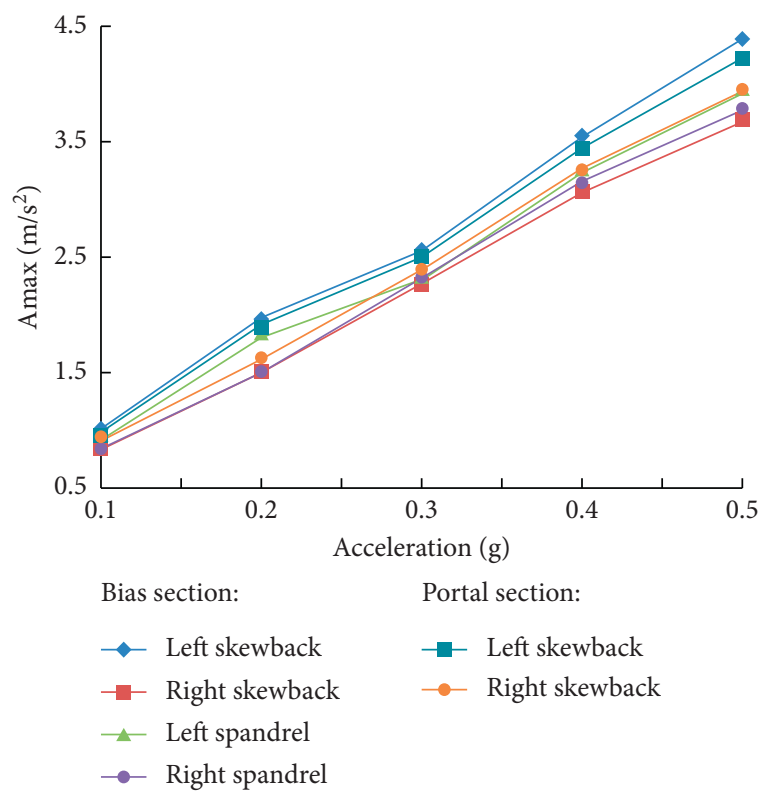

Figure 8: Peak contrast.

\section{Numerical Simulation Analysis}

4.1. Boundary Conditions. In order to establish an artificial boundary, the infinite continuous medium is cut off, and a continuous spring-damper-centralized mass system is applied at the cutoff, that is, the artificial boundary, as shown in Figure 11.

In order to overcome the inconvenience caused by the actual processing and calculation, we ignore the mass $M$ and fix one end of the damper connected to the mass $M$ to form the artificial boundary of the viscous damper + spring. The specific implementation method is shown in Figure 12. As shown in the figure, the coordinates $X$ and $Y$ in the figure are tangential to the artificial boundary, and $Z$ is the normal direction. The parameters of the physical elements on the viscoelastic artificial boundary node in the figure are

$$
\begin{aligned}
& K_{1}=K_{2}=\frac{2 G}{R} \sum_{i=1}^{I} A_{i}, \\
& C_{1}=C_{2}=\rho c_{s} \sum_{i=1}^{I} A_{i}, \\
& K_{3}=\frac{4 G}{R} \sum_{i=1}^{I} A_{i}, \\
& C_{3}=\rho c_{p} \sum_{i=1}^{I} A_{i} .
\end{aligned}
$$

Among them, $\Sigma \mathrm{Ai}$ is the area represented by the nodes on the artificial boundary, and for the case shown in Figure $11, I=4$.

4.2. Damage Model. It is difficult to analyze the concrete defect form and damage mechanism and determine the effective force area from the microscopic level, so indirect methods are needed to determine the material damage. The concrete damage constitutive model is used by Lubliner et al. [23]. The strain equivalence principle is proposed by Lubliner et al. [23]. It is assumed that the strain caused by stress acting on the damaged material is equivalent to the strain caused by effective stress acting on the nondestructive material. According to this principle, the actual constitutive relationship of the damaged material can be obtained from the nominal stress in the nondestructive material:

$$
\varepsilon=\frac{\sigma}{\widetilde{E}}=\frac{\widetilde{\sigma}}{E}=\frac{\sigma}{(1-D) E}, \quad \sigma=(1-D) E \varepsilon .
$$

Among them, $D$ is the elastic modulus damage parameter, $E$ is the elastic modulus of the material, and $\tilde{E}$ is the elastic modulus of the damaged material. From (3),

$$
D=1-\frac{\widetilde{E}}{E}
$$

Derivation of (3) gives

$$
\frac{\mathrm{d} \sigma}{\mathrm{d} \varepsilon}=\frac{\mathrm{d} E}{\mathrm{~d} \varepsilon}(1-D) \varepsilon+E(1-D)-E \varepsilon \frac{\mathrm{d} D}{\mathrm{~d} \varepsilon} .
$$

When the load is unloaded to a certain value, because the damage is irreversible, that is, the damage value is not reduced during the unloading process, that is, $\mathrm{d} / \mathrm{dE}=0$, where $E$ is the constant of the elastic modulus of the material without damage, so (5) can be changed to

$$
D=1-\frac{1}{E} \frac{\mathrm{d} D}{\mathrm{~d} \varepsilon}
$$

The elastic modulus of the damaged material is the slope of the unloading curve, so it can also be called the unloading modulus so that the elastic modulus of the damaged material can be obtained by unloading.

4.3. Model Establishment. The finite element program is used for numerical simulation. The stress and deformation of the biased tunnel are very complicated during the earthquake. It is a three-dimensional stress and deformation problem. In order to improve the accuracy of the simulation results, the three-dimensional problem is dealt with during modeling. The numerical simulation model is shown in Figure 13. This time the biased tunnel is compared with the unbiased tunnel. The elastoplastic constitutive model is adopted for the surrounding rock of the tunnel and the damage constitutive model is adopted for the tunnel lining. Seismic waves are input in the axial direction of the vertical tunnel, and the loading method is the same as the shaking table test.

\subsection{Damage Evolution and Cracking Mechanism of Tunnel Lining Opening}

4.4.1. Damage Evolution of Tunnel Lining Structure. According to the damage status of the tunnel lining under the earthquake, Figure 14 shows the damage cloud diagram of the tunnel lining when the damage expands at various 


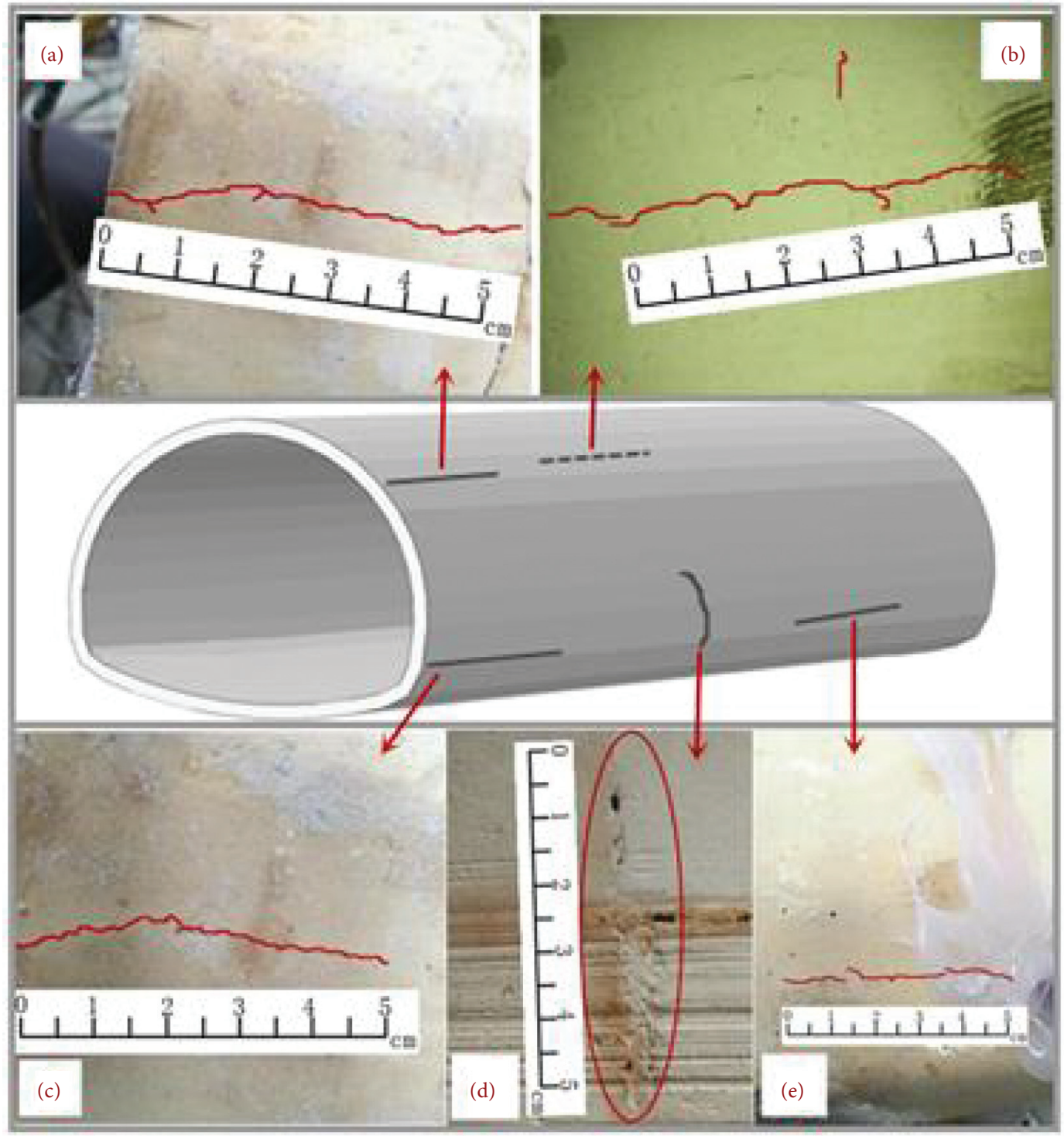

Figure 9: Lining crack. (a) Cracks in left skewback of bias section. (b) Cracks in right skewback of bias section. (c) Longitudinal cracks at right spandrel of portal section. (d) Ring crack of right spandrel in bias section. (e) Longitudinal crack of right spandrel in bias section.

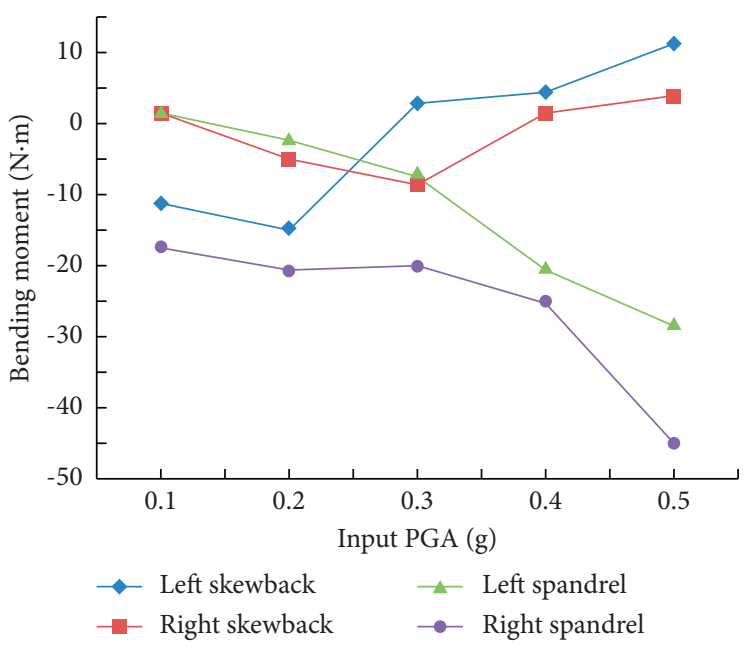

(a)

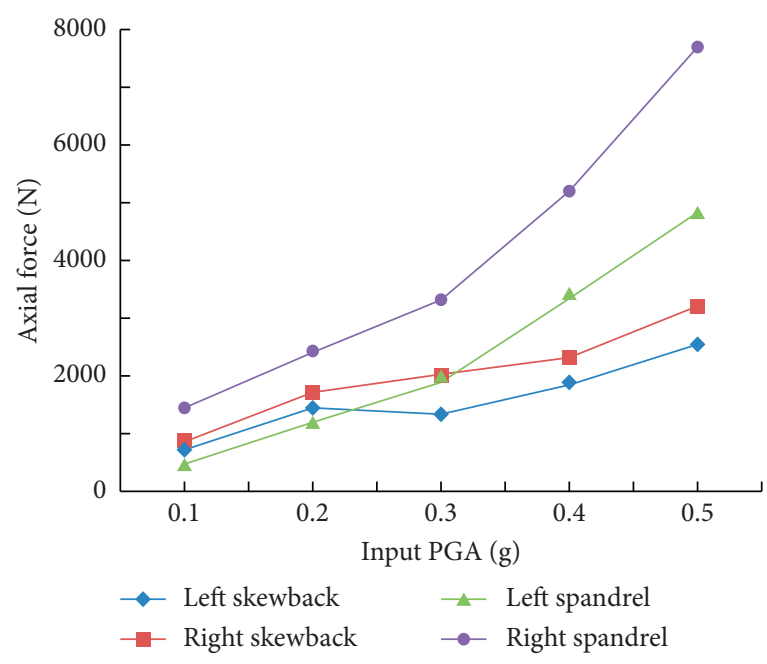

(b)

FiguRE 10: Time-history diagram of internal force. (a) Maximum bending moment. (b) Maximum axial force. 


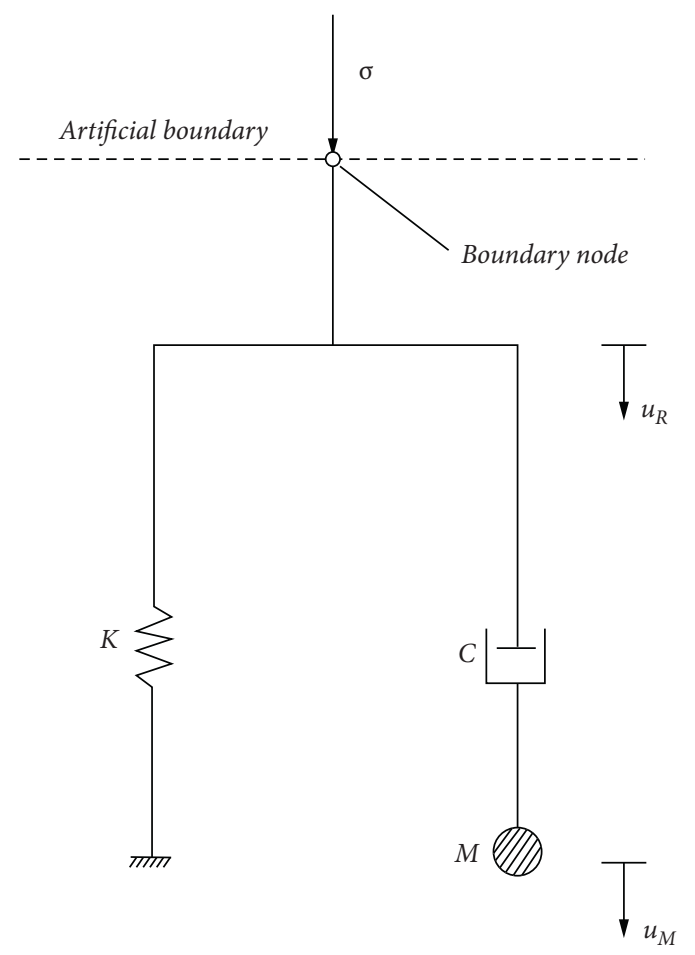

FIgURE 11: Normal boundary.

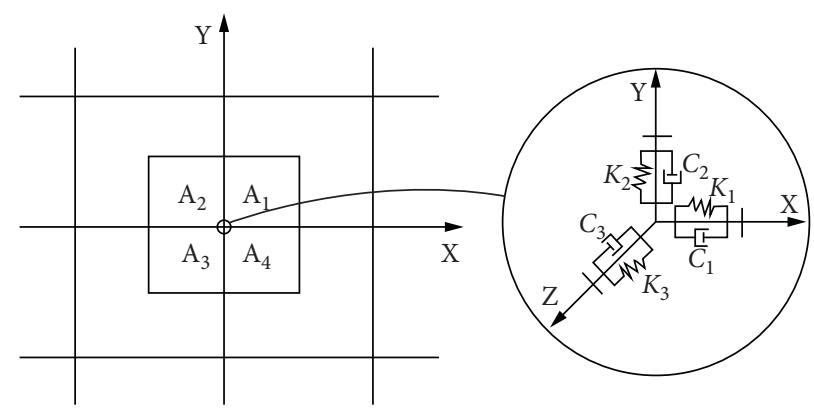

Figure 12: Artificial boundary.

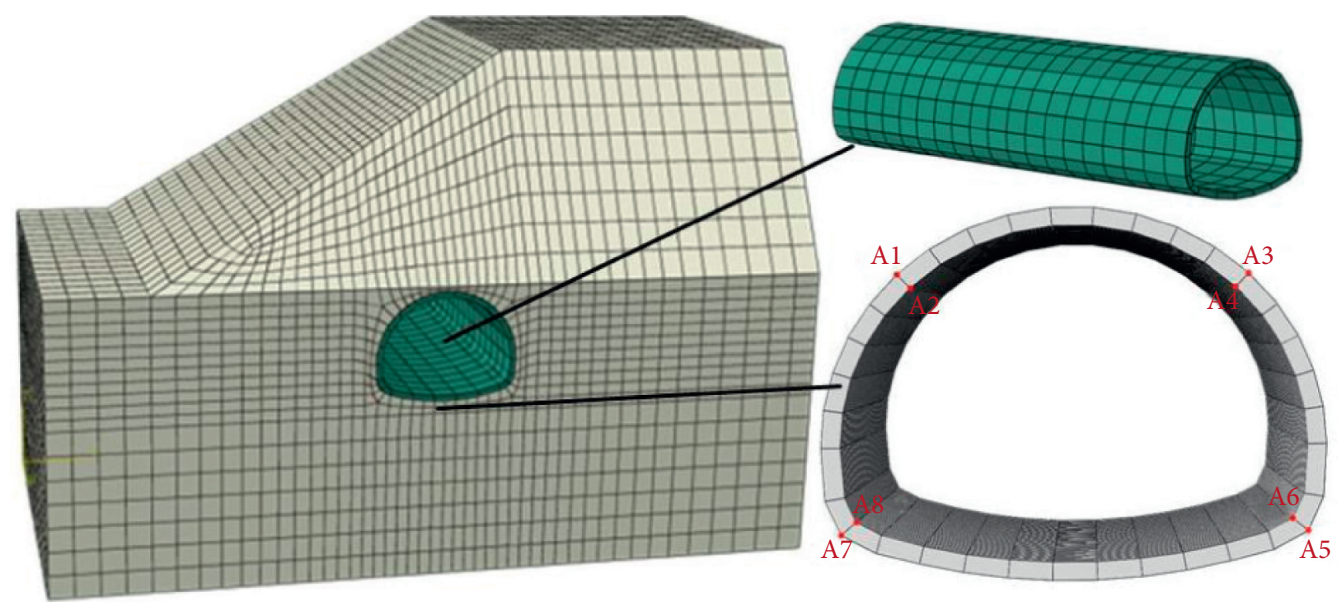

Figure 13: 3D bias model. 
DAMAGEC

(AVERAGE: 75\%)

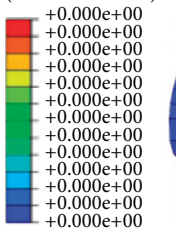

(AVERAGE: $75 \%$ )
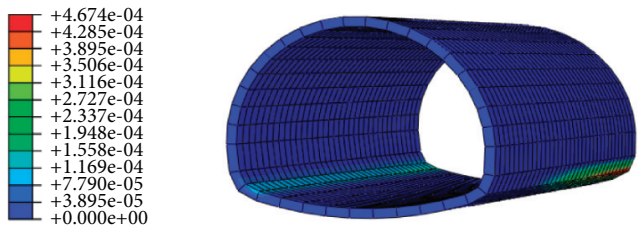

$t=1.994 \mathrm{~s}$

DAMAGEC

(AVERAGE: 75\%)
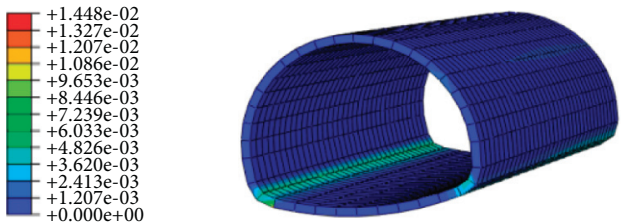

$t=2.991 \mathrm{~s}$

DAMAGEC

(AVERAGE: 75\%)
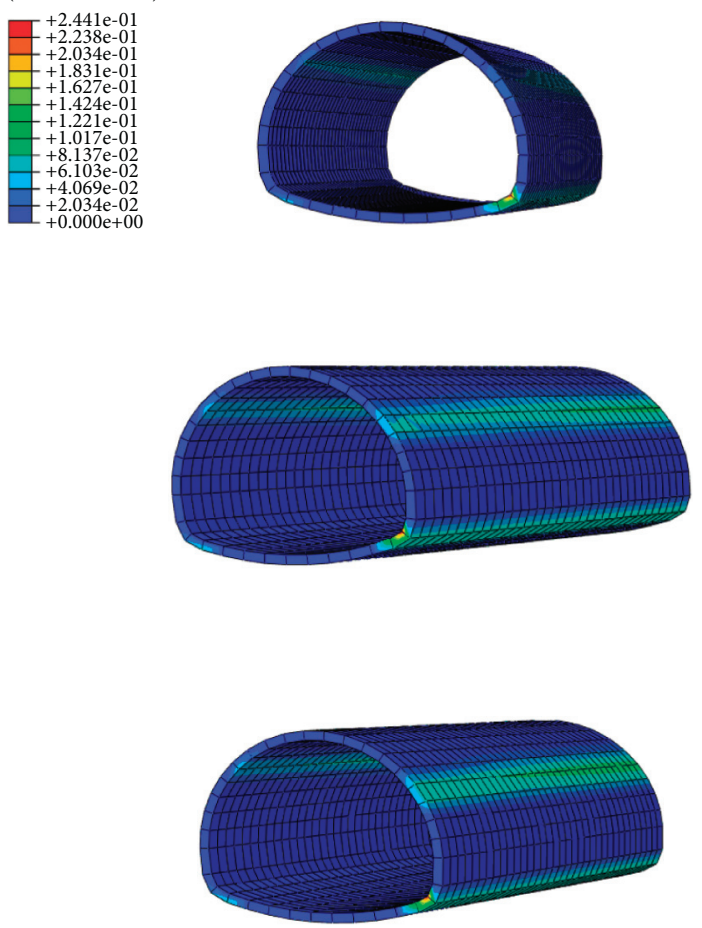

DAMAGEC

AVERAGE: 75\%
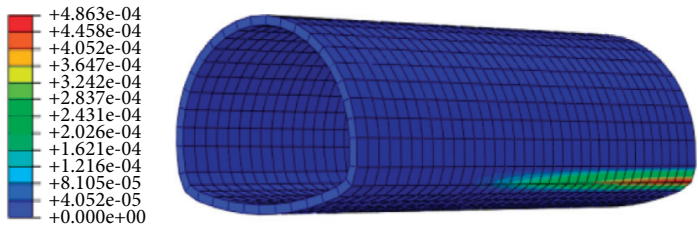

$t=1.970 \mathrm{~s}$

DAMAGEC

(AVERAGE: $75 \%$ )
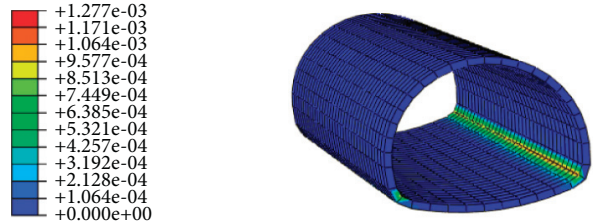

$t=2.310 \mathrm{~s}$

DAMAGEC

(AVERAGE: 75\%)
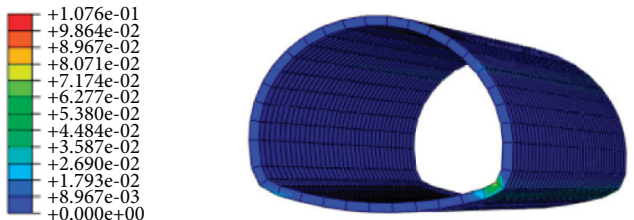

$t=5.256 \mathrm{~s}$

DAMAGEC (AVERAGE: 75\%)
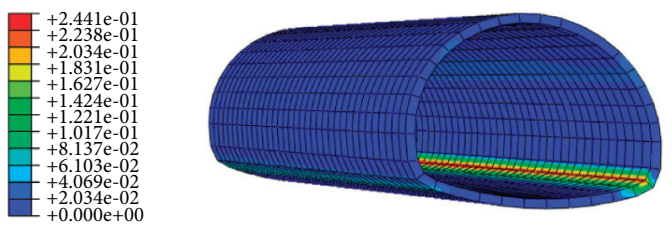

$t=5.386 \mathrm{~s}$

DAMAGEC

(AVERAGE: 75\%)
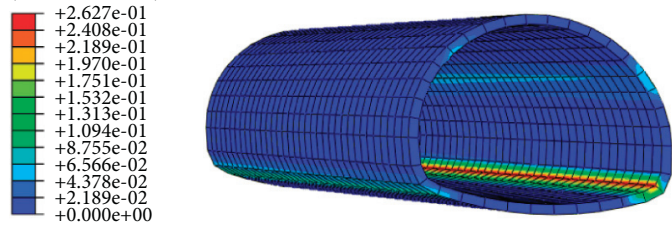

$t=15 \mathrm{~s}$

DAMAGEC (AVERAGE: 75\%)
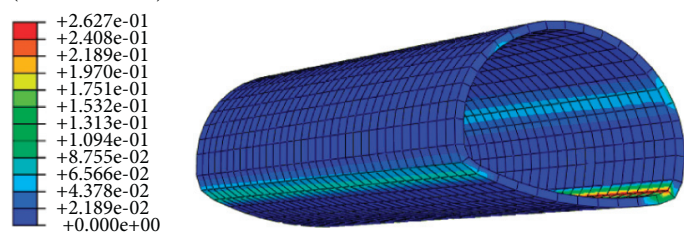

FIgURE 14: Damage map of tunnel lining.

time nodes. The direction of earthquake incidence is the same as the test direction, where damagec is the state variable for compression damage expansion and 1 represents complete damage and cracking of the unit while 0 represents no damage and cracking of the unit. $0.4 \mathrm{~g}$ was adopted as the peak acceleration of seismic waves in this section.

When $t=1.970 \mathrm{~s}$, it can be seen that the outer edge of the right arch foot at the tunnel opening section first appeared a 
S, Max. Principal (AVERAGE: 75\%)

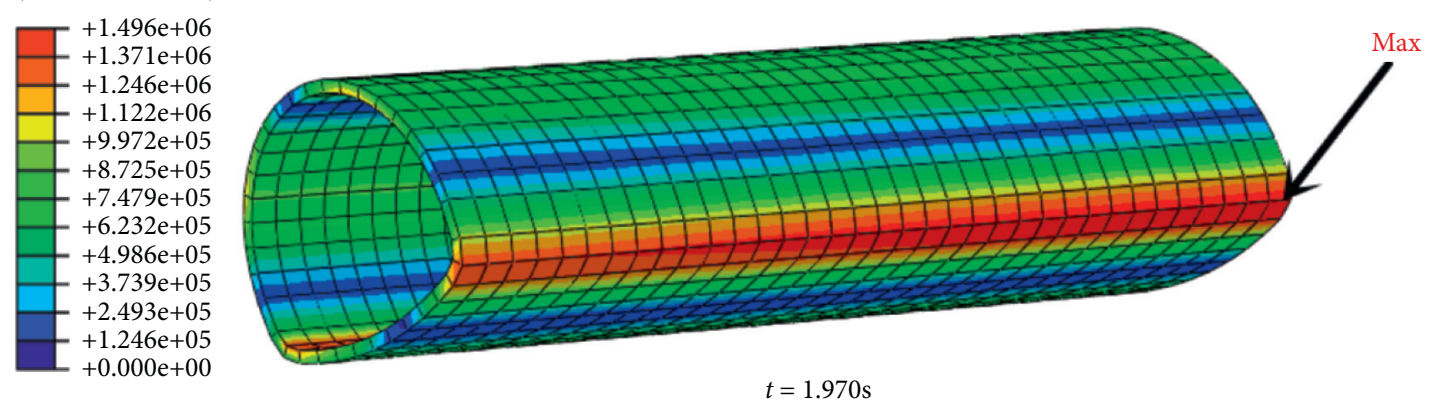

S, Mises (AVERAGE: $75 \%$ )

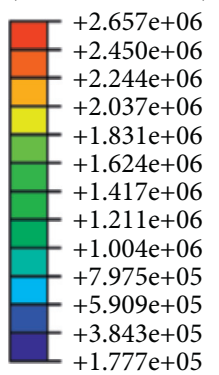

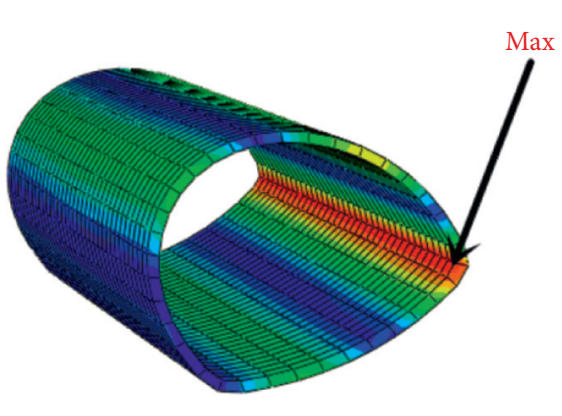

$t=2.310 \mathrm{~s}$
S, Max. Principal (AVERAGE: $75 \%$ )

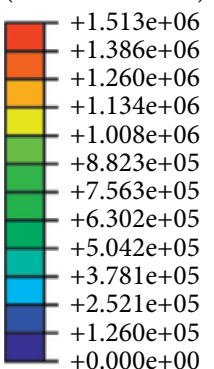
$+0.000 \mathrm{e}+00$

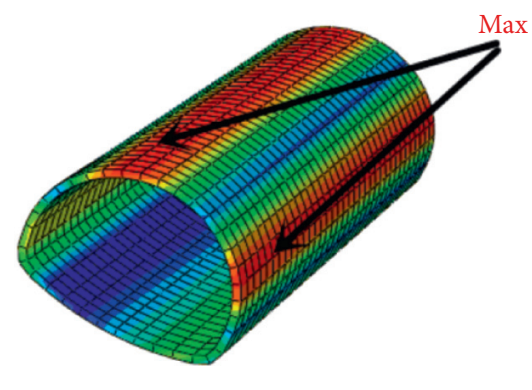

Figure 15: Maximum stress.

zone of compression damage under the action of axial ground motion along the tunnel through judging (Figure 14), and the damage was along the outer edge of the tunnel lining which is extend to the inner edge. When $t=1.994 \mathrm{~s}$, the damage area at the right spandrel continues to expand, and there is also a compression damage area at the left spandrel. When $t=2.310 \mathrm{~s}$, the left and right spandrel of the tunnel lining appear throughout the entire tunnel lining in the form of compression damage. When $t=2.911 \mathrm{~s}$, the damage area of the left spandrel of the tunnel lining section appeared, and the damage of the tunnel lining was further expanded until $t=5.256 \mathrm{~s}$, and at this point, the right spandrel of the tunnel lining appeared in the form of the damage. It can be seen at $t=5.386 \mathrm{~s}$ that when the left and right spandrel and left and right skewback of the tunnel lining show damage areas with the increase of earthquake time, it shows continuous expansion trend, and the damage area continues to expand until $t=15 \mathrm{~s}$. The damage areas of the left and right spandrel and the left and right spandrel of the tunnel lining became gradually stabilized and no longer expanded. When $t=39.95 \mathrm{~s}$, it is the cloud image of the final compressed damage area presented by the tunnel lining at the end of the earthquake.

In the damage distribution diagram in Figure 14, it is not difficult to find that the left spandrel of the tunnel lining of the tunnel section, the right spandrel, the left skewback, and the right skewback are the areas which are most prone to compressive damage from the beginning to the last compression of damage area under earthquake when tunnel is under a shallow-buried conduction, among which the right arch leg of the tunnel lining has the largest compression damage. At the same time, it was found the damage of tunnel lining rapidly expanded within $2 \mathrm{~s}$ under the action of earthquake between $t=1.970 \mathrm{~s}$ and $t=2.911 \mathrm{~s}$, which has obvious impact on tunnel lining.

\subsubsection{Analysis of the Maximum Principal Stress Seismic} Dynamic Response of the Tunnel Lining Structure. In order to further study the damage and cracking behavior of the tunnel lining structure, the skewback and spandrel points on the tunnel lining of the opening section are selected as key points (Figure 13). Figure 15 shows the cloud diagrams of maximum principal stress of the tunnel lining structure at the earthquakes of $1.970 \mathrm{~s}, 2.310 \mathrm{~s}$, and $39.95 \mathrm{~s}$.

When the tunnel lining structure is subjected to damage, namely, $t=1.970 \mathrm{~s}$, the cloud diagram of principal stress cloud diagram of the tunnel lining structure is shown in the figure. At the point, the maximum principle stress appears at skewback along negative direction of $X$-axis, which was $1.496 \mathrm{MPa}$. When $t=2.310 \mathrm{~s}$, that is, the maximum principal stress at this moment is $2.657 \mathrm{MPa}$ when the maximum peak intensity of the earthquake action is reached. At this time, the stress value of the tunnel lining structure along the $X$-axis skewback side basically reaches $2.244 \mathrm{MPa}$, indicating the maximum principal stress. The damage crack at the maximum position is caused by the concrete tensile strength that reaches the limit value. When $t=39.95 \mathrm{~s}$, the maximum value of the tunnel maximum principal stress is located at the positive abutment position of the $X$-axis which is $1.513 \mathrm{MPa}$. At this time, the damage area of the tunnel lining abutment and arch foot tends to be stable, and the maximum principal stress of the tunnel lining structure is fully released. 


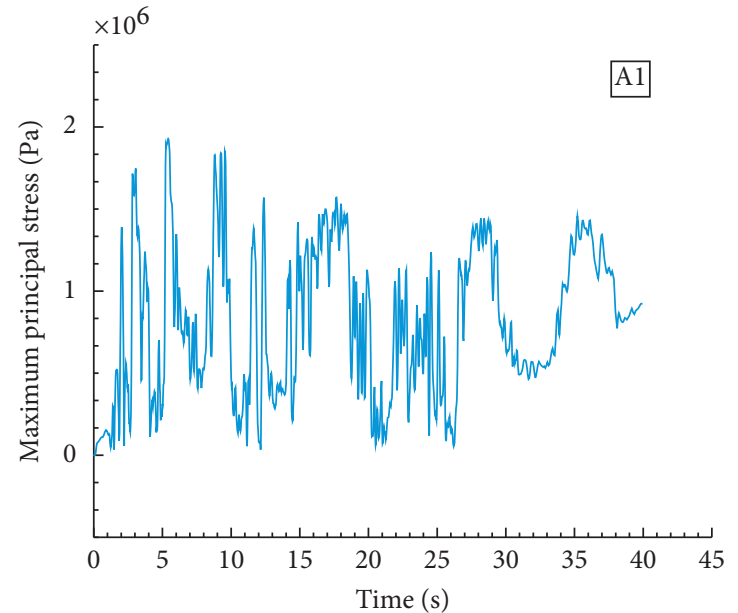

(a)

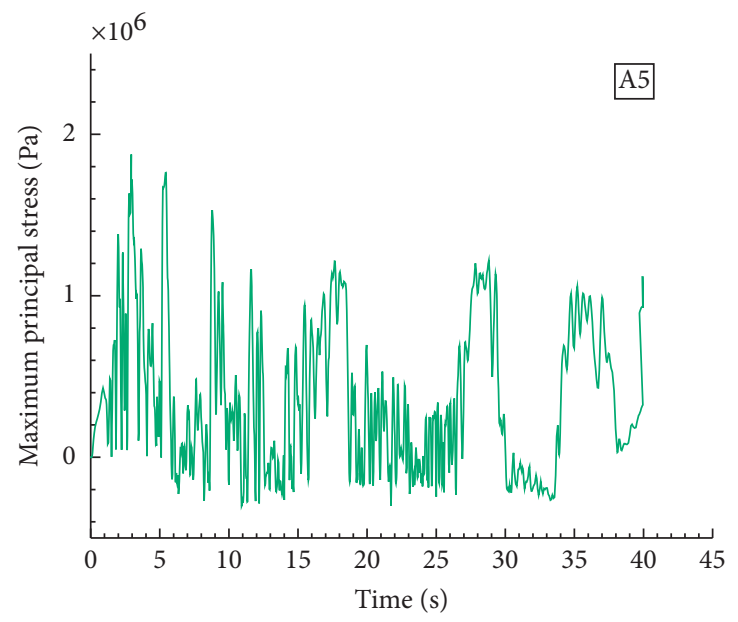

(c)

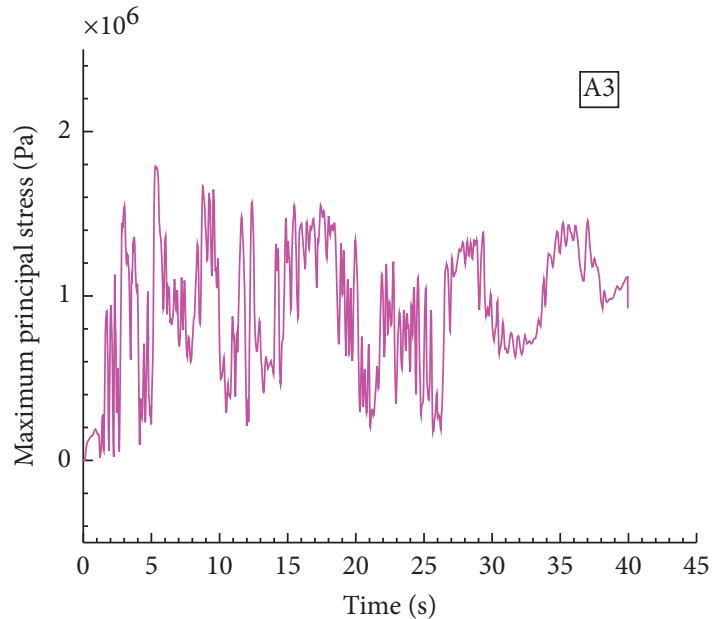

(b)

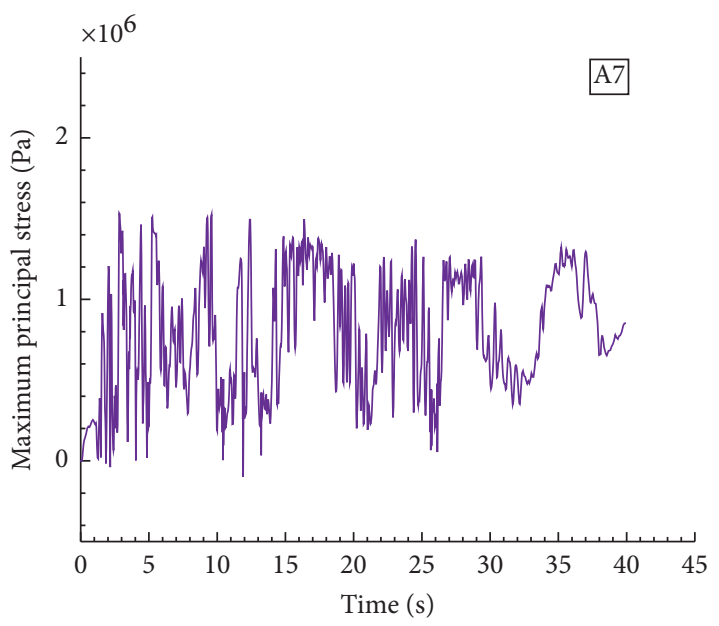

(d)

FIGURE 16: Time history of maximum principal stress response.

TABle 5: Key points A1-A8 maximum principal stress value and corresponding time C25 =1.78.

\begin{tabular}{lccccccrr}
\hline Key point & A1 & A2 & A3 & A4 & A5 & A6 & A7 & A8 \\
\hline Stress $(\mathrm{MPa})$ & 1.993 & 1.838 & 1.788 & 1.848 & 1.875 & 1.993 & 1.533 \\
Time $(\mathrm{s})$ & 5.418 & 9.565 & 5.289 & 5.386 & 2.939 & 5.321 & 2.825 & 9.257 \\
\hline
\end{tabular}

And, the maximum value decreases and a corresponding position shift occurs.

Figure 16 shows the time-history curve of maximum principal stress at key points of the tunnel lining structure. According to Figure 16 and Table 5, it can be seen that the maximum principal stress of $1.57 \mathrm{MPa}$ first appears at point A7 when $t=2.825 \mathrm{~s}$, and when $t=2.939 \mathrm{~s}$, that is, the maximum principal stress of 1.875 appears at the right skewback of the tunnel lining structure. At the moment, the crack is observed at $A 5$, and the maximum principal stress of $\mathrm{A} 3, \mathrm{~A} 6, \mathrm{~A} 4$, and $\mathrm{A} 1$ reached $1.78 \mathrm{MPa}$ successively in the following 7 seconds. The maximum principal stress of A2 and A8 finally reached $1.78 \mathrm{MPa}$, and later, crack was witnessed. After the peak value of the seismic wave, the maximum principal stress of the corresponding key points at the various moments of the damage and crack propagation of the tunnel lining structure in the later period reached the peak value. However, all the principle stresses were less than 1.78 $\mathrm{MPa}$, which indicates that the concrete cracking in the later period can realize the development of crack under less stress, which will cause damage to the concrete. When $t=39.95 \mathrm{~s}$, the maximum principal stresses at A1-A8 key points are all closer to $1.0 \mathrm{MPa}$ when ground motion stops.

4.4.3. Analysis of the Minimum Principal Stress Seismic Dynamic Response of the Tunnel Lining Structure. Figure 17 shows the cloud diagrams of minimum principal stress of the tunnel lining structure at the earthquakes times of 
S. Min. Principal (Avg: 75\%)

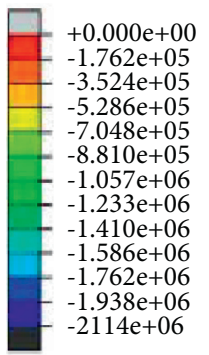

Min: $-2.114 \mathrm{e}+06$

Elem: CQ-1.1174 Node: 2424

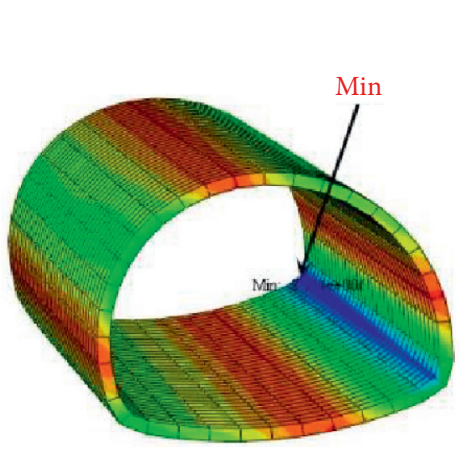

Min. Principal (Avg: $75 \%$ )

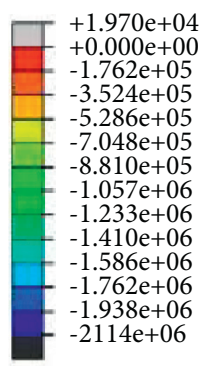

Min: $-1.327 \mathrm{e}+06$

Elem: CQ-1.1004

Node: 2075

$$
\mathrm{t}=1.970 \mathrm{~s}
$$$$
\mathrm{t}=2.310 \mathrm{~s}
$$

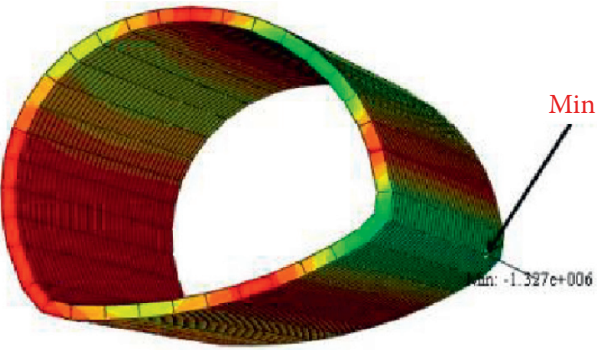

$\mathrm{t}=2.310 \mathrm{~s}$

S. Min. Principal (Avg: 75\%)

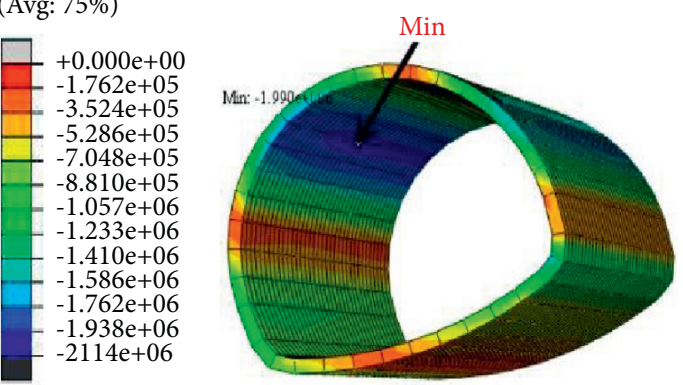

Min: $-1.990 \mathrm{e}+06$

Elem: CQ-1.537

Node: 1143

$$
t=39.95 \mathrm{~s}
$$

Figure 17: Minimum stress.

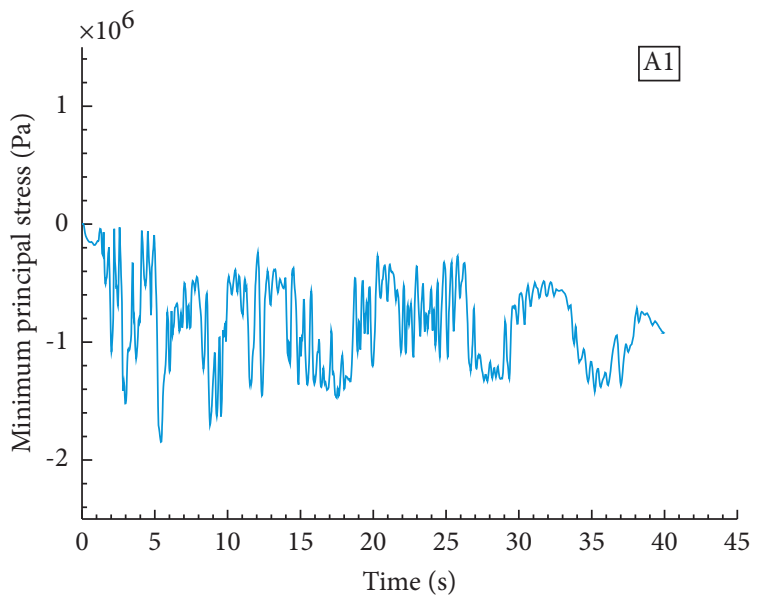

(a)

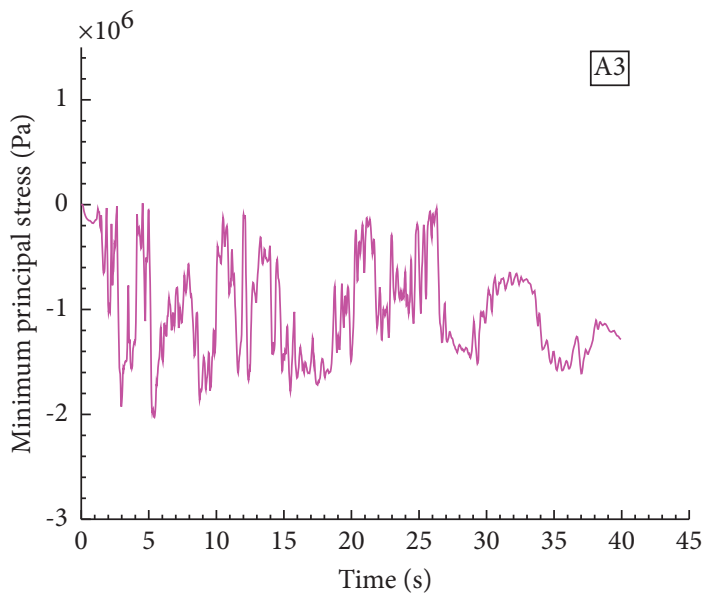

(b)

Figure 18: Continued. 


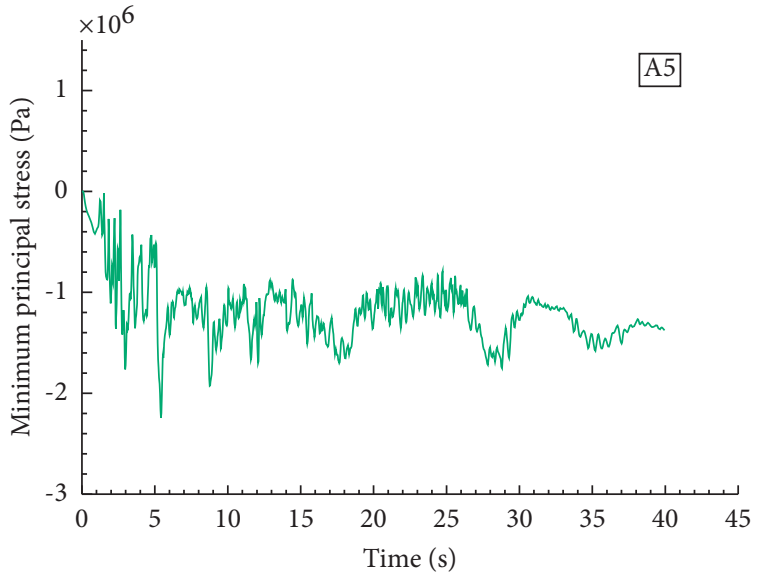

(c)

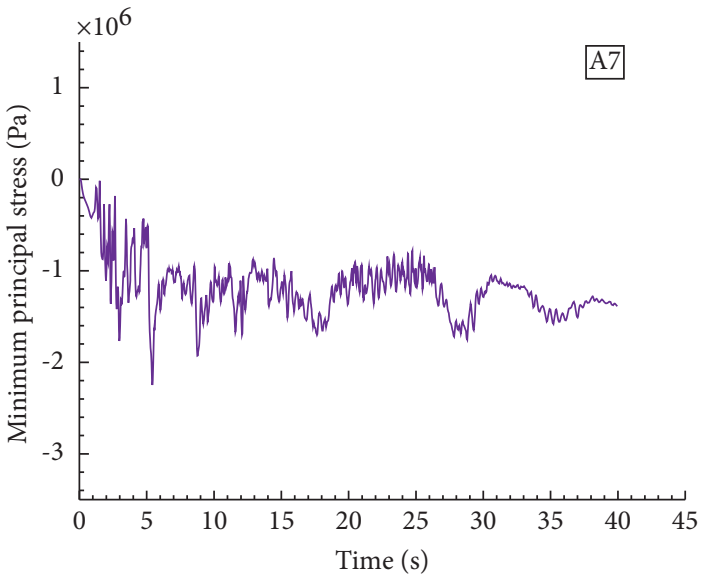

(d)

FIgURE 18: Time history of minimum principal stress response.

TABLE 6: Minimum principal stress values at key points A1-A8 and corresponding times C25=1.78

\begin{tabular}{|c|c|c|c|c|c|c|c|c|}
\hline Key point & A1 & $\mathrm{A} 2$ & $\mathrm{~A} 3$ & $\mathrm{~A} 4$ & A5 & A6 & A7 & A8 \\
\hline Stress $(\mathrm{MPa})$ & -1.847 & -2.791 & -2.029 & -1.512 & -2.244 & -3.501 & -2.248 & -2.551 \\
\hline Time (s) & 5.218 & 5.450 & 5.418 & 5.386 & 5.328 & 5.468 & 5.428 & 4.388 \\
\hline
\end{tabular}

$1.970 \mathrm{~s}, 2.310 \mathrm{~s}$, and $39.95 \mathrm{~s}$. When $t=1.970 \mathrm{~s}$, a large stress was generated at the right skewback of the tunnel lining structure, and the minimum principal stress reached $-2.114 \mathrm{MPa}$. At this time, the cracking occurred at the skewback of the tunnel lining structure. When $t=2.310 \mathrm{~s}$, the minimum principal stress is $-1.327 \mathrm{MPa}$, and the minimum principal stress witnessed an increment. Since the skewback of the tunnel is under high pressure for a long time, the cracks at the skewback is quickly generated within $1 \mathrm{~s}$. When $t=39.95 \mathrm{~s}$, the minimum principal stress was transferred to the arch shoulder, and the minimum principal stress was $1.990 \mathrm{MPa}$.

Figure 18 shows time-history curve of the minimum stress at the key points of the tunnel lining structure A1-A8. By combining Table 6 and Figure 18, it can be seen that the minimum principal stress from A1 to A8 occurs at approximately $5.0 \mathrm{~s}$, and the minimum principal stress of each key point stress is $-2.791 \mathrm{MPa}$. The cure of minimum principal stress at each key point fluctuated slightly but all tended to be stable. It can be seen from the time chart of the minimum principal stress that the stress curve at the right skewback (A5, A6) fluctuates relatively sharply. Meanwhile, it can be found that the tunnel lining structure has a significant bias effect comparing left and right skewback and left and right spandrel at same time.

4.4.4. Verify Numerical Model. Combining the results of seismic tunnel damage investigations with model test failure locations is used to verify the maximum and minimum principal stresses and damage locations of the numerical simulation.

\section{Conclusion}

In this paper, a series of shaking table tests and numerical simulations were performed to the shallow-buried biased tunnels under seismic action. And, a detailed description of the design and numerical simulation of the shaking table test are also made. The damage of the tunnel lining is studied by sweep frequency of white noise and combining seismic excitation. The results of the analysis are discussed in terms of lining damage, lining acceleration, and axial force of bending moment, and this research gets these conclusions:

(1) The lining at entrance of the shallow-buried biased tunnel exhibits a significant biasing effect.

(2) The biasing effect promotes the unfavorable stress distribution of the tunnel structure.

(3) Meanwhile, the serious stress concentration occurs at the lining spandrel and skewback. The unfavorable stress distribution is more likely to cause damage to the tunnel. The tunnel lining earthquake damage easily occurs at the spandrel and skewback and gradually expands with the continuous damage of the earthquake.

(4) Under the action of the earthquake, the axial force of the tunnel structure shows a compressive effect and bending moment demonstrates a cyclic stress of tension and compression, where the bending moment at the right skewback displays the largest internal force, and it is also a serious damage area. 


\section{Data Availability}

The data used to support the findings of this study are available from the corresponding author upon request.

\section{Conflicts of Interest}

The authors declare that they have no conflicts of interest.

\section{Acknowledgments}

This study was financially supported by the National Natural Science Foundation of China, under Grant no. 51708373. The authors thank National Natural Science Foundation of China and all who have contributed to this study.

\section{References}

[1] J. J. Zhang and M. F. Lei, "Safety analysis of biased tunnel construction technology," Highway Engineer, vol. 36, no. 5, pp. 144-148, 2011.

[2] Z. Chen, C. Shi, T. Li, and Y. Yuan, "Damage characteristics and influence factors of mountain tunnels under strong earthquakes," Natural Hazards, vol. 61, no. 2, pp. 387-401, 2012.

[3] Y. M. A. Hashash, J. J. Hook, B. Schmidt, and J. I-Chiang Yao, "Seismic design and analysis of underground structures," Tunnelling and Underground Space Technology, vol. 16, no. 4, pp. 247-293, 2001.

[4] W. L. Wang, T. T. Wang, J. J. Su, C. H. Lin, C. R. Seng, and T. H. Huang, "Assessment of damage in mountain tunnels due to the Taiwan Chi-Chi Earthquake," Tunnelling and Underground Space Technology, vol. 16, no. 3, pp. 133-150, 2001.

[5] D. R. Brunsdon, R. A. Davey, C. J. Graham et al., "The CHICHI, taiwan earthquake OF 21 september 1999," Bulletin of the New Zealand Society for Earthquake Engineering, vol. 33, no. 2, pp. 105-167, 2000.

[6] Z. Wang, B. Gao, Y. Jiang, and S. Yuan, "Investigation and assessment on mountain tunnels and geotechnical damage after the Wenchuan earthquake," Science in China - Series E: Technological Sciences, vol. 52, no. 2, pp. 546-558, 2009.

[7] T. Li, "Damage to mountain tunnels related to the Wenchuan earthquake and some suggestions for aseismic tunnel construction," Bulletin of Engineering Geology and the Environment, vol. 71, no. 2, pp. 297-308, 2012.

[8] H. Yu, J. Chen, A. Bobet, and Y. Yuan, "Damage observation and assessment of the Longxi tunnel during the Wenchuan earthquake," Tunnelling and Underground Space Technology, vol. 54, pp. 102-116, 2016.

[9] Y. M. A. Hashash, D. Park, and J. I.-C. Yao, "Ovaling deformations of circular tunnels under seismic loading, an update on seismic design and analysis of underground structures," Tunnelling and Underground Space Technology, vol. 20, no. 5, pp. 435-441, 2005.

[10] R. J. Bathurst, S. Zarnani, and A. Gaskin, "Shaking table testing of geofoam seismic buffers," Soil Dynamics and Earthquake Engineering, vol. 27, no. 4, pp. 324-332, 2007.

[11] J.-H. Hwang and C.-C. Lu, "Seismic capacity assessment of old Sanyi railway tunnels," Tunnelling and Underground Space Technology, vol. 22, no. 4, pp. 433-449, 2007.
[12] S. Kontoe, L. Zdravkovic, D. M. Potts, and C. O. Menkiti, "Case study on seismic tunnel response," Canadian Geotechnical Journal, vol. 45, no. 12, pp. 1743-1764, 2008.

[13] Z. Y. Chen and H. Shen, "Dynamic centrifuge tests on isolation mechanism of tunnels subjected to seismic shaking," Tunnelling and Underground Space Technology, vol. 42, no. 5, pp. 67-77, 2014.

[14] X. Zhang, Y. Jiang, and S. Sugimoto, "Seismic damage assessment of mountain tunnel: a case study on the Tawarayama tunnel due to the 2016 Kumamoto Earthquake," Tunnelling and Underground Space Technology, vol. 71, pp. 138-148, 2018.

[15] M. Geniş, "Assessment of the dynamic stability of the portals of the Dorukhan tunnel using numerical analysis," International Journal of Rock Mechanics and Mining Sciences, vol. 47, no. 8, pp. 1231-1241, 2010.

[16] L. Tao, S. Hou, X. Zhao et al., "3-D shell analysis of structure in portal section of mountain tunnel under seismic SH wave action," Tunnelling and Underground Space Technology, vol. 46, pp. 116-124, 2015.

[17] J. Lai, H. Fan, B. Liu, and T. Liu, "Analysis of seismic response of shallow large section multi-arch tunnel," Procedia Engineering, vol. 15, pp. 5473-5477, 2011.

[18] S. Wang, J. Li, H. Luo, and H. Zhu, "Damage identification in underground tunnel structures with wavelet based residual force vector," Engineering Structures, vol. 178, pp. 506-520, 2019.

[19] M. Varma, V. B. Maji, and A. Boominathan, "Numerical modeling of a tunnel in jointed rocks subjected to seismic loading," Underground Space, vol. 4, 2018.

[20] Z. Z. Wang, Y.-J. Jiang, C. A. Zhu, and T. C. Sun, "Shaking table tests of tunnel linings in progressive states of damage," Tunnelling and Underground Space Technology, vol. 50, pp. 109-117, 2015.

[21] F. Wang, X. Jiang, and J. Niu, "The large-scale shaking table model test of the shallow-bias tunnel with a small clear distance," Geotechnical \& Geological Engineering, vol. 35, no. 3, pp. 1093-1110, 2017.

[22] Q. Xu, P. Cheng, H. Zhu et al., "Experimental study and numerical simulation on progressive failure characteristics of the fault-crossing tunnel surrounding rock," Chinese Journal of Rock Mechanics and Engineering, 2016.

[23] J. Lubliner, J. Oliver, S. Oller, and E. Oñate, "A plastic-damage model for concrete," International Journal of Solids and Structures, vol. 25, no. 3, pp. 299-326, 1989. 